\title{
Microstructures, Thermal and Tensile Properties of Sn-Zn-Ga Alloys
}

\author{
Jenn-Ming Song, Nai-Shuo Liu and Kwang-Lung Lin* \\ Department of Materials Science and Engineering, National Cheng Kung University, Tainan 701, Taiwan, R. O. China
}

The effects of Ga content on the microstructure, thermal behavior and mechanical properties of Sn-Zn eutectic alloy were examined in this study. Results show that Ga was dissolved in both $\mathrm{Sn}$ and $\mathrm{Zn}$ phases. This gave rise to irregular eutectic structure with misaligned, less distributed massive Zn-rich phase, relatively low melting point, and solid solution strengthening effect. Due to the inhomogeneous dissolution feature of $\mathrm{Ga}$ in $\mathrm{Sn}$ matrix, Sn-Zn-Ga alloys exhibit a broad melting range and an alternate normal-irregular eutectic structure. Notably, the addition of $\mathrm{Ga}$ into the $\mathrm{Sn}-\mathrm{Zn}$ alloy will improve the tensile strength without reducing the ductility when the Ga content ranges from 0.05 to 1 mass $\%$.

(Received September 26, 2003; Accepted January 9, 2004)

Keywords: tin-zinc-gallium, lead-free solder, thermal behavior, microstructure, mechanical properties

\section{Introduction}

It is desirable that a $\mathrm{Pb}$-free solder has approximately the same melting temperature or solidus/liquidus range as that of conventional $\mathrm{Sn}-\mathrm{Pb}$ solder. $\mathrm{Sn}-\mathrm{Zn}$ eutectic alloy has recently been considered as a candidate for lead-free solder material because of its low melting point $\left(198^{\circ} \mathrm{C}\right)$, excellent mechanical properties and low cost. ${ }^{1-3)}$ However, the Sn-Zn eutectic alloy exhibits problems of poor wetting, easy oxidation, and dross formation. ${ }^{4,5)}$ It should be of interest to develop a new $\mathrm{Sn}-\mathrm{Zn}$ based alloy that addresses these problems.

Alloying elements of $\mathrm{In},{ }^{6)} \mathrm{Bi}^{7)} \mathrm{Al}^{7},{ }^{8} \mathrm{Ag}^{9)}$ and rare earths (RE, mainly $\mathrm{La}$ and $\mathrm{Ce})^{10,11)}$ were chosen to lower the melting temperature or improve the wettability. As for the effect of the alloying additions on melting point, previous investigations indicated that $\mathrm{Bi}$ and In effectively decrease the melting temperature of $\mathrm{Sn}-\mathrm{Zn}$ alloy, while there is no significant change in the melting point with small additions of $\mathrm{Ag}, \mathrm{Al}$ and $\mathrm{RE}$. Among these, when the $\mathrm{Ag}$ content exceeds 0.5 mass $\%$, it will result in an off-eutectic structure and thus an endothermic tail on DSC curve representing the fusion of primary $\mathrm{Sn}$ phase found at temperatures slightly higher than eutectic point. ${ }^{12)}$

The addition of $\mathrm{Bi}$, In, $\mathrm{Al}$ and $\mathrm{RE}$ into the $\mathrm{Sn}-\mathrm{Zn}$ system significantly increases the tensile strength and reduces elongation. In contrast, a recent report ${ }^{13)}$ demonstrated that $\mathrm{Ag}$ addition leads to a higher ductility, reduced tensile strength and lower elastic modulus. In addition, dendritic Ag$\mathrm{Zn}$ intermetallics, ${ }^{14)} \mathrm{Al}-\mathrm{Zn}-\mathrm{Sn}^{15}$ ) and $\mathrm{Sn}-\mathrm{RE}$ compounds ${ }^{11)}$ can be observed in Sn-Zn-Ag, Sn-Zn-Al and Sn-Zn-Re solders respectively. Bi precipitates are finely dispersed and In might form solid solution with $\mathrm{Sn}$. In-rich phase can also be found in Sn-Zn-In alloys. ${ }^{6}$

$\mathrm{Ga}$, of which melting point is $29.78^{\circ} \mathrm{C}$, has been applied to increase the strength, enhance fatigue life and lower the melting temperature of solders. ${ }^{14,16,17)}$ Worthy of notice is that, $\mathrm{Ga}$ is capable of suppressing dross formation when the molten solder is exposed to air. ${ }^{16)}$ To develop an appropriate replacement for $\mathrm{Sn}-\mathrm{Pb}$ alloy, $\mathrm{Ga}$ seems to be a potential alloying element in alloy design for $\mathrm{Sn}-\mathrm{Zn}$ solders. This
Table 1 Chemical composition of the specimens investigated (mass\%).

\begin{tabular}{llll}
\hline Sample & $\mathrm{Ga}$ & $\mathrm{Zn}$ & $\mathrm{Sn}$ \\
\hline $0 \mathrm{Ga}$ & 0 & 8.6 & Bal. \\
$0.05 \mathrm{Ga}$ & 0.05 & 8.6 & Bal. \\
$0.1 \mathrm{Ga}$ & 0.1 & 8.6 & Bal. \\
$0.25 \mathrm{Ga}$ & 0.25 & 8.6 & Bal. \\
$0.5 \mathrm{Ga}$ & 0.5 & 8.5 & Bal. \\
$1.0 \mathrm{Ga}$ & 1.0 & 8.5 & Bal. \\
$1.8 \mathrm{Ga}$ & 1.8 & 8.4 & Bal. \\
\hline
\end{tabular}

present study aimed to investigate the properties of $\mathrm{Sn}-\mathrm{Zn}-\mathrm{Ga}$ alloys, including microstructural, thermal and tensile properties.

\section{Experimental Procedures}

Master alloys of near-eutectic Sn-Zn solder alloy and those with a Ga content of $0.05 \sim 1.8$ mass $\%$ were prepared by melting pure tin, pure zinc and pure gallium in a high frequency induction furnace. The chemical compositions of the solder alloys investigated are listed in Table 1 where the samples are designated according to their compositions. These prepared alloy ingots were re-melted and cast into a Yshaped graphite mold with a constant thickness of $2.4 \mathrm{~mm}$.

The thermal behavior of the solders was investigated with differential scanning calorimetry (DSC) and cooling curve. DSC analysis was conducted at a constant heating rate of $0.5^{\circ} \mathrm{C} / \mathrm{min}$ from 25 to $300^{\circ} \mathrm{C}$. Cooling curves were obtained by inserting a thermocouple into $200 \mathrm{~g}$ of molten solder placed in a $\mathrm{MgO}$ crucible. The initial temperature of the molten solder was above $600^{\circ} \mathrm{C}$.

Phase identification of the various solders was performed by an X-ray diffractometer operated at $30 \mathrm{kV}$ and $\mathrm{Cu}-\mathrm{K} \alpha$ radiation was used, with a scanning speed of $1^{\circ} / \mathrm{min}$. The microstructures of the solders were investigated with a scanning electron microscope (SEM) and electron probe microanalysis (EPMA). 


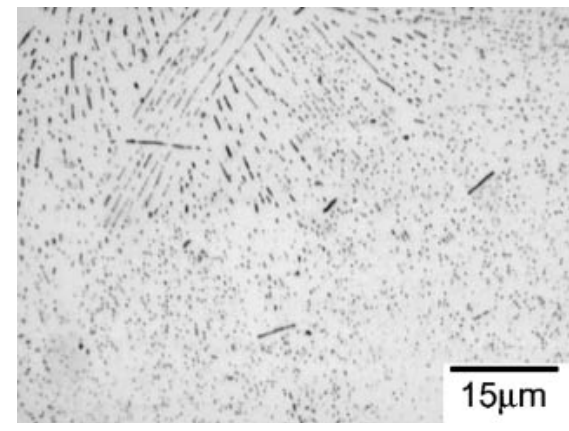

(a)

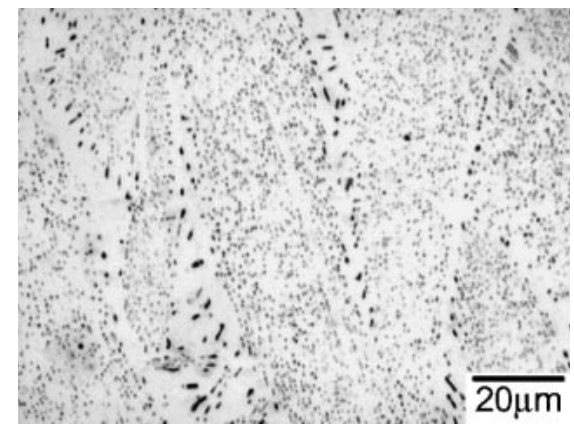

(d)

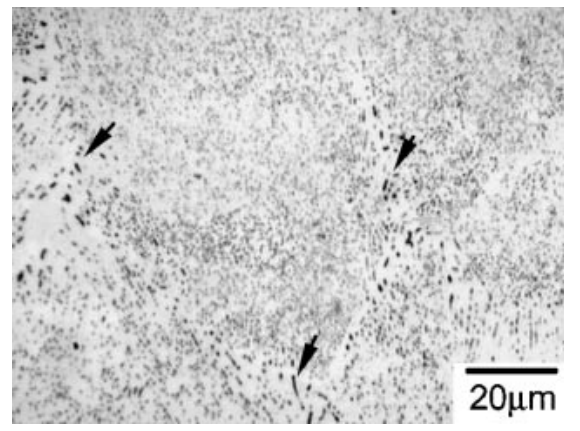

(b)

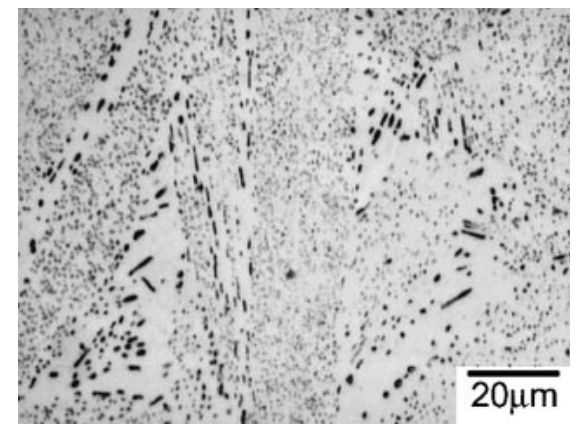

(e)

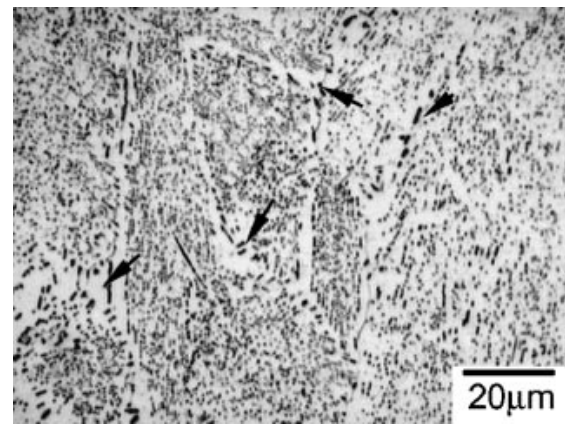

(c)

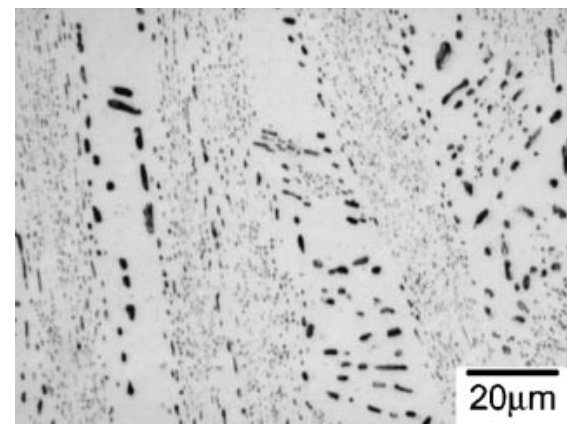

(f)

Fig. 1 Microstructure of Sn-Zn-Ga alloys with various Ga contents: (a) 0 mass $\%$, (b) 0.05 mass $\%$, (c) 0.25 mass $\%$, (d) 0.5 mass $\%$, (e) 1 mass $\%$, (f) 1.8 mass $\%$.

\section{Results}

\subsection{Microstructural features}

Figure 1 shows the microstructure of the $\mathrm{Sn}-\mathrm{Zn}$ alloys investigated. The $0 \mathrm{Ga}$ specimen, Fig. 1(a), displays a typical microstructure of rapidly-solidified $\mathrm{Sn}-\mathrm{Zn}$ eutectic structure. Each eutectic cell possessed aligned acicular Zn-rich particles. With a small addition of Ga (Figs. 1(b) and (c)), a few coarse $\mathrm{Zn}$ particles, indicated by the arrows, were observed in the vicinity of eutectic cell boundaries. These irregular $\mathrm{Zn}$ particles existing in-between eutectic cells are no longer aligned. When the Ga content reached 0.5 mass $\%$ and above, it was found that broad irregular regions and normal eutectic structure form alternately (Figs. 1(d)-(f)).

This morphological transition of the Zn-rich particles takes place gradually as seen in Fig. 2(a). The magnified structure of the high-Ga specimen $(1.8 \mathrm{Ga})$, Fig 2(a), shows that on the edge of the normal eutectic region the $\mathrm{Zn}$ particles were tending to become massive toward the irregular structure. The Ga content, Fig. 2(b), of the matrix Sn phase also increased gradually. The backscattering electron image, Fig. 3(a), of the near cell boundary area between a normal eutectic structure (lower right corner) and an irregular region (upper left corner) also illustrates that the $\mathrm{Zn}$ needles became coarser from the normal cell to irregular region. Worthy of notice is that $\mathrm{Ga}$ was detected in both the $\mathrm{Sn}$ matrix and $\mathrm{Zn}$-rich particles. It also shows that the $\mathrm{Ga}$ content in $\mathrm{Sn}$ phase between these two regions also changed gradually, as indicated by the variation in brightness of Ga signals. The quantitative analysis results, Fig. 3(b), evidence that the Sn phase within the irregular structure possesses a relatively higher Ga content than the normal structure. These results indicate that there might exist a critical Ga content of about 1.6 mass $\%$ for the microstructural transition. The normal Sn$\mathrm{Zn}$ eutectics become coarse and disoriented at above 1.6 mass $\%$ for $\mathrm{Ga}$ content.

The XRD patterns, Fig. 4, of the samples with varying Ga content, indicate that no other phase than the $\beta$-Sn and $\mathrm{Zn}$ rich phases could be identified. However, an increase in Ga content resulted in a slight shift of the Sn (220) and Sn (211) peaks toward a higher angle, while the diffraction peaks of $\mathrm{Zn}$ phase move to a lower angle.

\subsection{Thermal properties}

Figure 5 shows the DSC endothermic peaks of the samples used upon heating. It reveals that the wedge-shaped peak for the $\mathrm{Sn}-\mathrm{Zn}$ eutectic reaction became less sharp with a higher $\mathrm{Ga}$ content. The whole peak obviously shifts to a lower temperature when the Ga content exceeds 0.1 mass $\%$. The transition points for each specimen, including the temperatures of the solidus, liquidus, peak and onset, are shown in Fig. 6(a). The onset temperature, regarded as the melting point, is determined by first identifying the steepest portion of the low temperature side of the heat absorption, defining the slope at that point, and extrapolating this slope line to the temperature axis of zero differential heat flow. ${ }^{18)}$ All the transition temperatures of the $\mathrm{Sn}-\mathrm{Zn}$ solders decreased with a higher Ga content, especially the solidus temperature. The solidius temperature, the starting temperature of the endothermic peak, is as low as $167.5^{\circ} \mathrm{C}$ for the $1.8 \mathrm{Ga}$ specimen. $\mathrm{Ga}$ addition also significantly expands the solidus/liquidus range. By computing the peak area of the DSC curves, the 


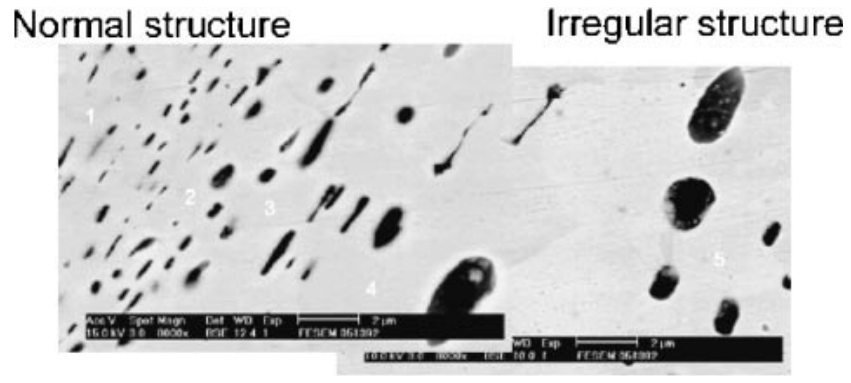

(a)

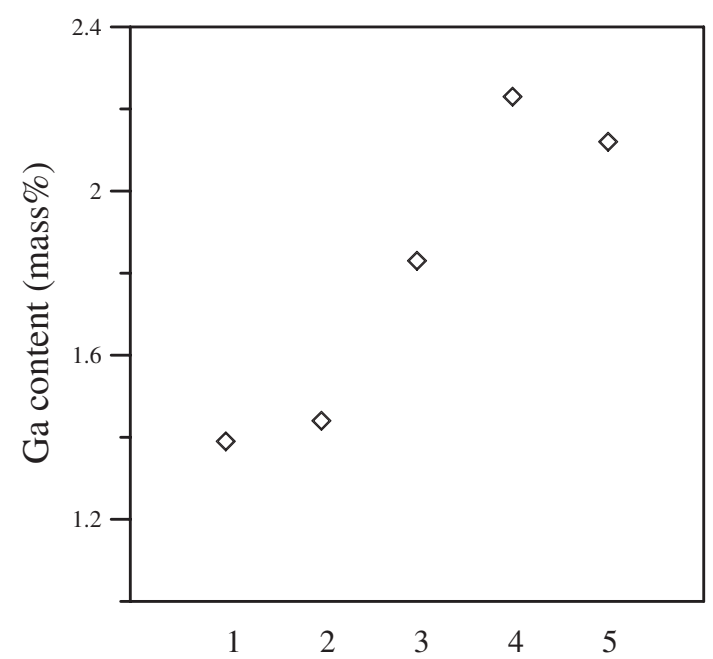

(b) enthalpy of fusion (latent heat) of these specimens was determined. Figure 6(b) indicates that the addition of Ga did not significantly affect the latent heat in spite of the change in the shape of the endothermic peak. In addition, the Sn-Zn alloys examined in this study exhibited a higher enthalpy of fusion in comparing with eutectic $\mathrm{Sn}-\mathrm{Pb}$ and $\mathrm{Sn}-\mathrm{Ag}$ solders. $^{19)}$

The cooling curves of the specimens, Fig. 7, indicate that all the samples show a eutectic feature and no inflection point above the eutectic temperature. However, there existed some differences between the unalloyed and Ga-containing specimens. An increase in $\mathrm{Ga}$ addition lowers the temperature of the plateau after the supercooling signal and makes the plateau become a descending curve.

\subsection{Tensile properties}

An increase in Ga content increases the tensile strength of the specimens, as seen in Fig. 8. The total elongation, Fig. 9, remains almost constant, but drops drastically as the Ga content reaches 1.8 mass $\%$. Notably, the uniform elongation rises with respect to the increasing $\mathrm{Ga}$ content at above 0.5 mass $\%$.

Figure 10 illustrates the tensile fracture surface, and reveals that all the specimens show a ductile dimple pattern. Remarkably, there were some smooth facets, Fig 10(g), on the fracture surface of the $1.8 \mathrm{Ga}$ specimen. These smooth appearances correspond to the surface of irregular massive Zn particles as seen in Fig. 10(h).

Fig. 2 (a) Magnified structure of the region in-between normal and irregular structures of the $1.8 \mathrm{Ga}$ sample; (b) Ga content of the marked areas in (a) (analyzed by EDS).

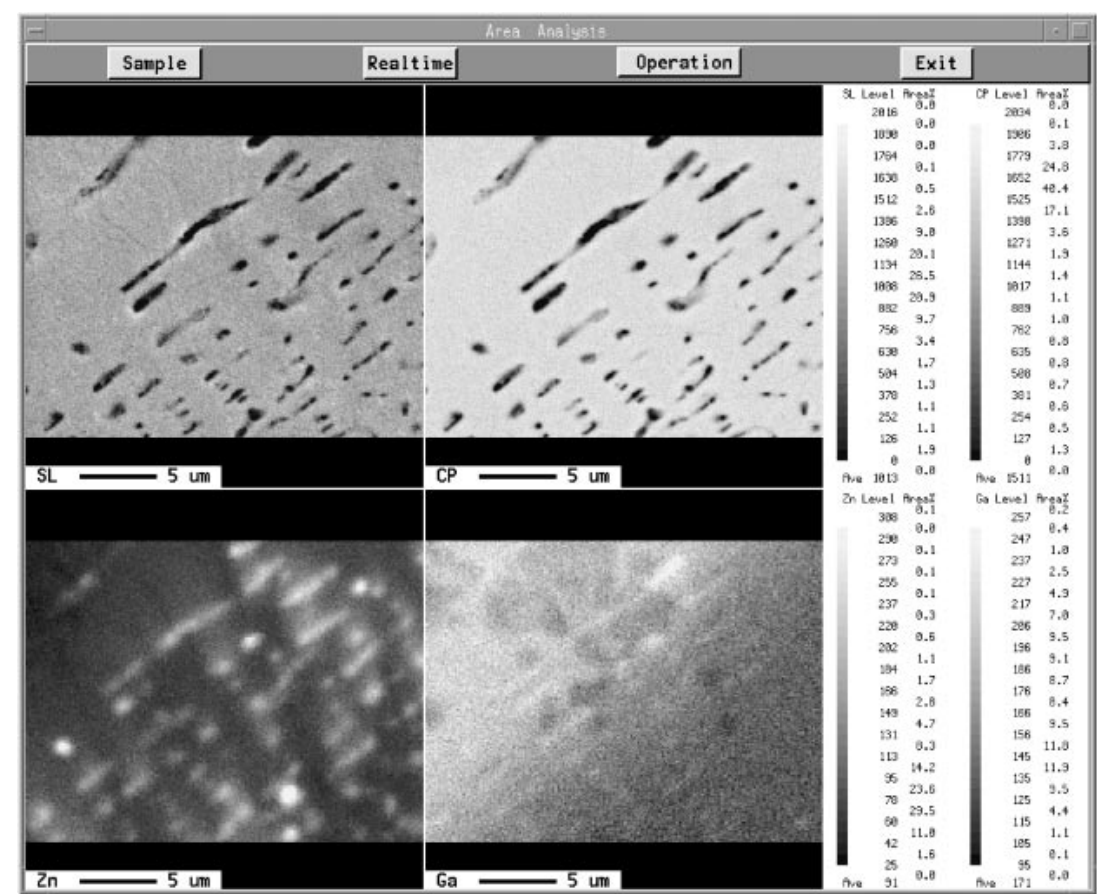

(a)

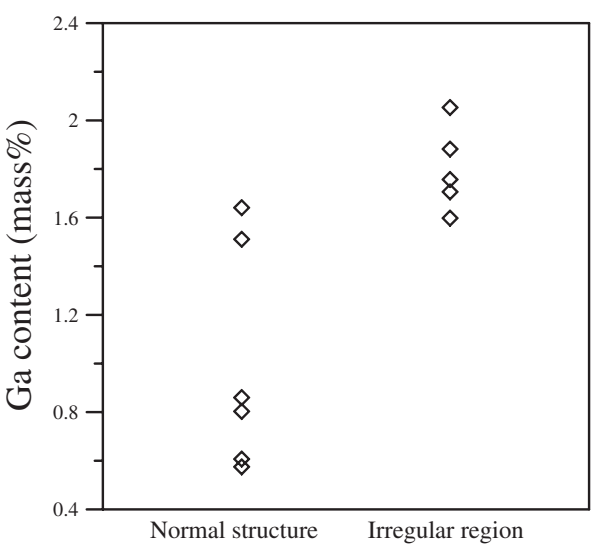

(b)

Fig. 3 (a) Backscattering electron image of the $1.8 \mathrm{Ga}$ sample; (b) quantitative analysis results of Ga using WDS. 


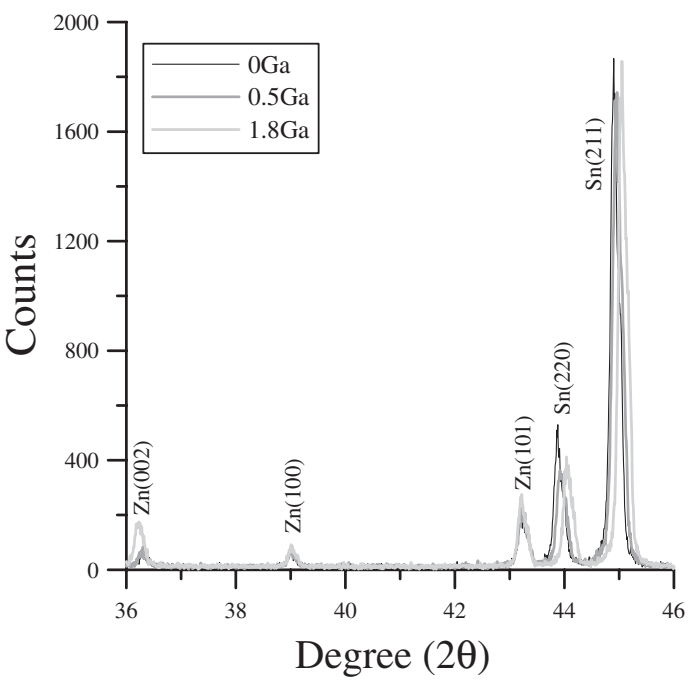

(a)

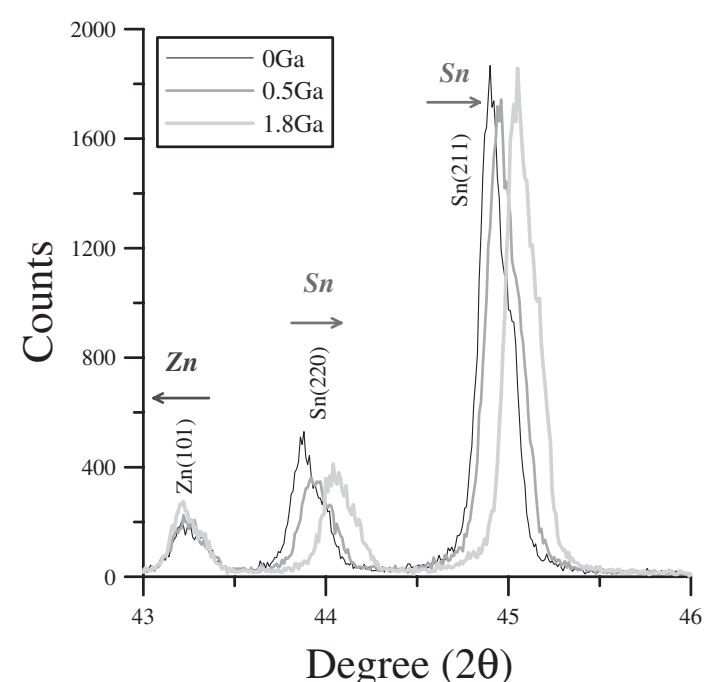

(b)

Fig. 4 (a) $\mathrm{X}$ ray diffraction patterns of the samples with different $\mathrm{Ga}$ contents; (b) magnified patterns ranging from $43^{\circ}$ to $46^{\circ}$ of (a).

\section{Discussion}

\subsection{Formation of the normal-irregular structure of $\mathrm{Sn}$ - Zn-Ga alloys}

The results of microstructural investigation and elemental analysis show that the irregular structure possesses a relatively higher $\mathrm{Ga}$ content. The $\mathrm{Ga}$ content increases continuously from normal structure to irregular structure. The addition of Ga causes the shift in the diffraction peaks of both Sn and Zn (Fig. 4). These phenomena can be ascribed to the dissolution of $\mathrm{Ga}$ in the $\mathrm{Sn}$ and $\mathrm{Zn}$ phases and the inhomogeneous distribution of $\mathrm{Ga}$.

According to the $\mathrm{Ga}-\mathrm{Sn}^{20)}$ and $\mathrm{Ga}-\mathrm{Zn}^{21)}$ binary phase diagrams, Ga may form solid solutions with $\mathrm{Sn}$ and $\mathrm{Zn}$. The atomic radii of tin, zinc, and gallium are $0.158 \mathrm{~nm}, 0.133 \mathrm{~nm}$, and $0.135 \mathrm{~nm}$ respectively. ${ }^{22)}$ The reduced lattice parameter of $\mathrm{Sn}$ (the X-ray diffraction peaks shift to a higher angle) and enlarged lattice parameter of $\mathrm{Zn}$ (the diffraction peaks shift to a lower angle) demonstrate that $\mathrm{Ga}$ was dissolved in both $\mathrm{Sn}$ and $\mathrm{Zn}$.

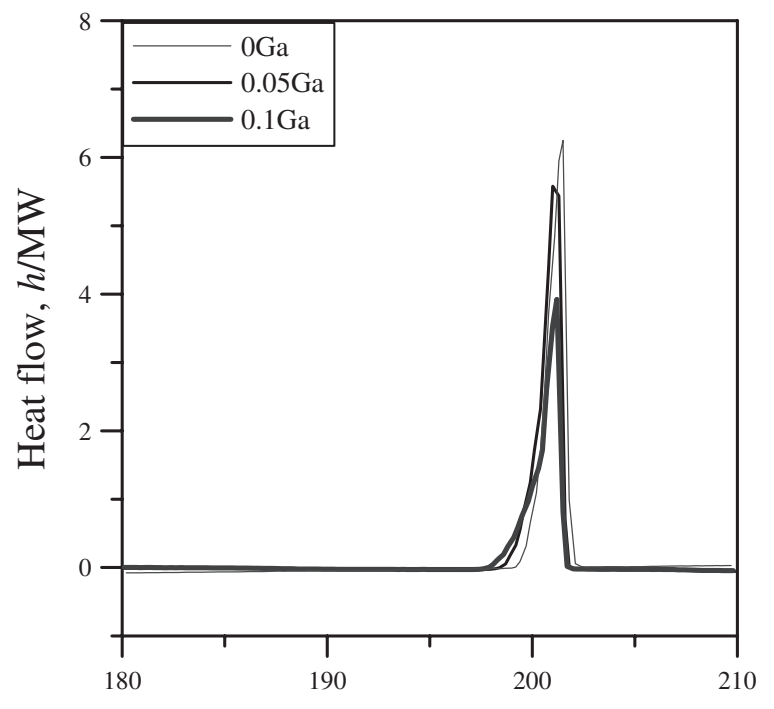

Temperature, $T /{ }^{\circ} \mathrm{C}$

(a)

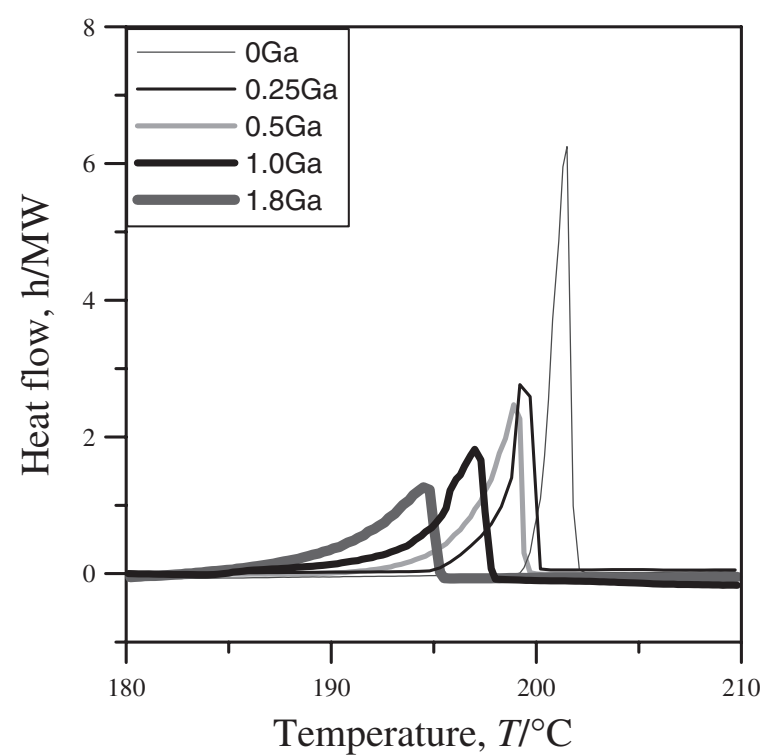

(b)

Fig. 5 DSC curves of the eutectic Sn-Zn alloy and (a) low Ga samples and (b) high Ga samples upon heating.

Previous reports have classified the structure of the eutectic Sn-Zn alloy with a broken-lamellar appearance as an anomalous non-faceted (N.F.)/faceted(F) eutectic system. ${ }^{23)}$ The $\mathrm{Zn}$-phase possesses a fibrous appearance in the case of high growth rate and lies generally along the growth axis. $^{23,24)}$ Moreover, the entropy of solution $(\Delta S)$ for $\mathrm{Zn}$ rich phase in the $\mathrm{Sn}-\mathrm{Zn}$ eutectic ${ }^{23)}$ was estimated to be $7.6 \mathrm{cal} \mathrm{K}^{-1} \mathrm{~mol}^{-1}$.

As mentioned above, adding Ga can cause changes in the lattice parameters of $\mathrm{Sn}$ and $\mathrm{Zn}$, and subsequently an increase in entropy of solution, which may result in the morphological change of eutectic microstructure from broken lamellar to irregular flake. ${ }^{25)}$

At a small addition of $\mathrm{Ga}$ (less than 0.25 mass $\%$ ), Ga atoms tend to segregate at the cell boundary regions. The segregation of Ga breaks up the interface between the cells and 


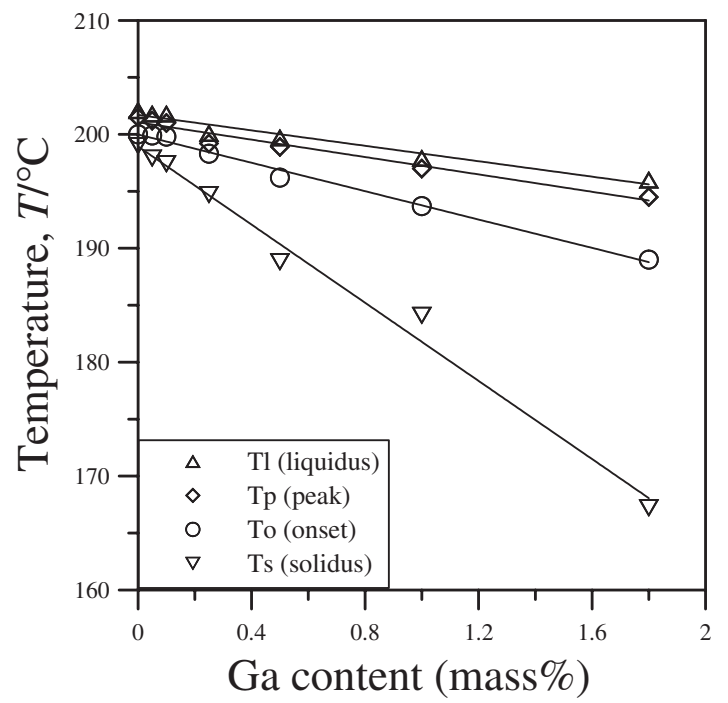

(a)

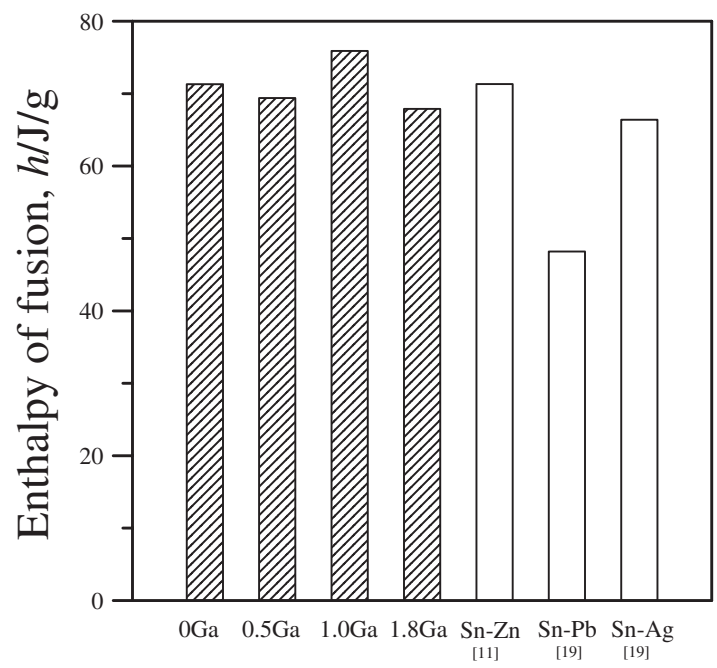

(b)

Fig. 6 (a) Transition points as a function of $\mathrm{Ga}$; (b) latent heat of $\mathrm{Sn}-\mathrm{Zn}-\mathrm{Ga}$ alloys and several solder alloys.

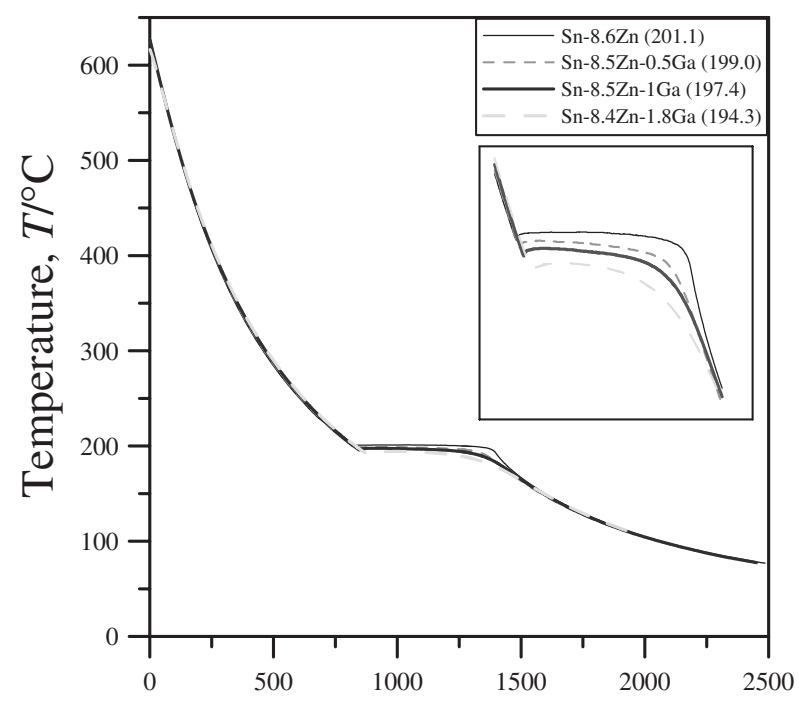

Cooling time, $t / \mathrm{sec}$

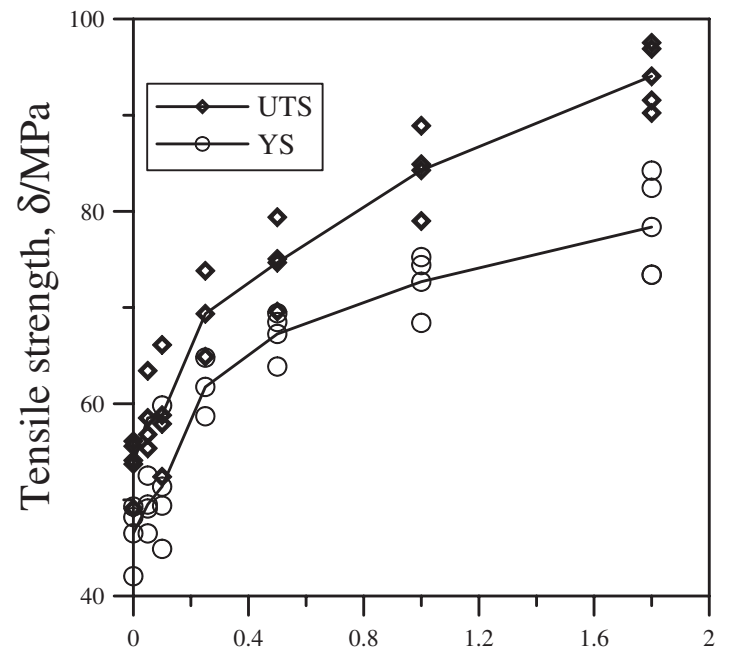

Ga content (mass\%)

Fig. 8 Tensile strength with respect to the Ga content.

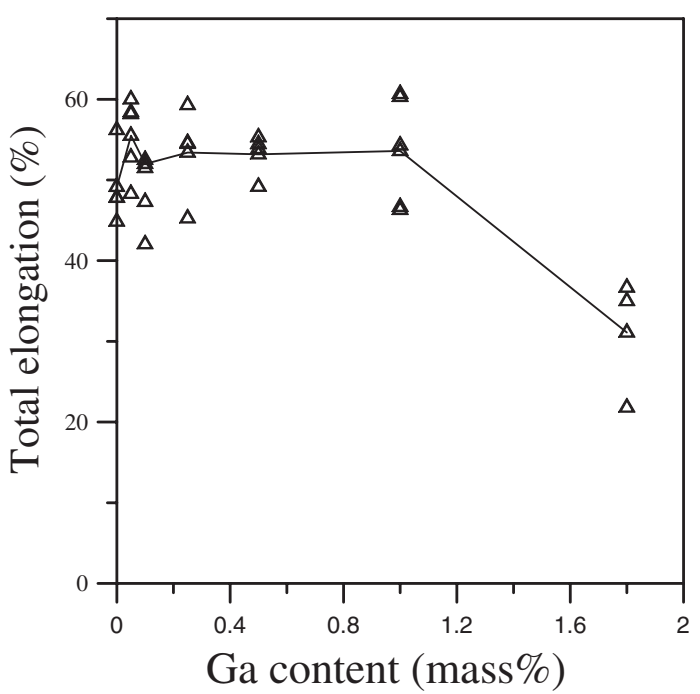

(a)

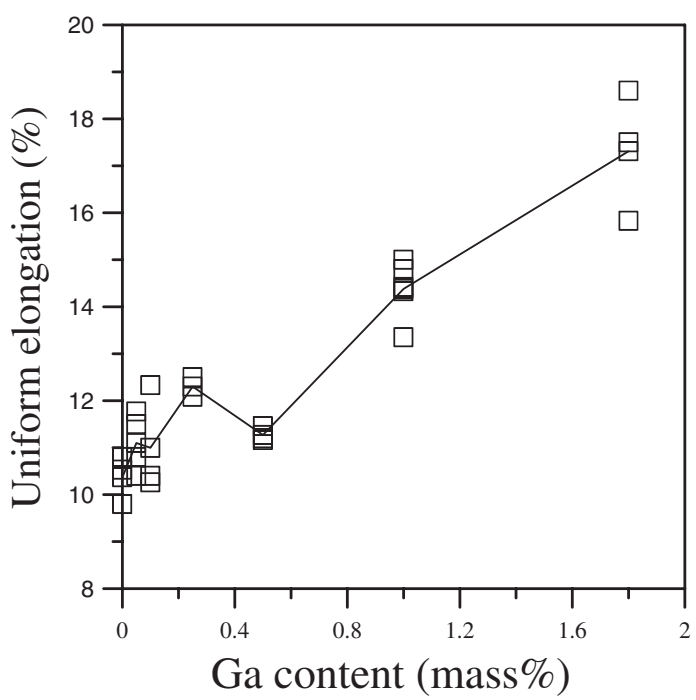

(b)
Fig. 7 Cooling curves of the samples with different Ga contents, the highest temperature values within the plateaus are also indicated.
Fig. 9 Elongation of the specimens with respect to the Ga content: (a) total elongation and (b) uniform elongation. 

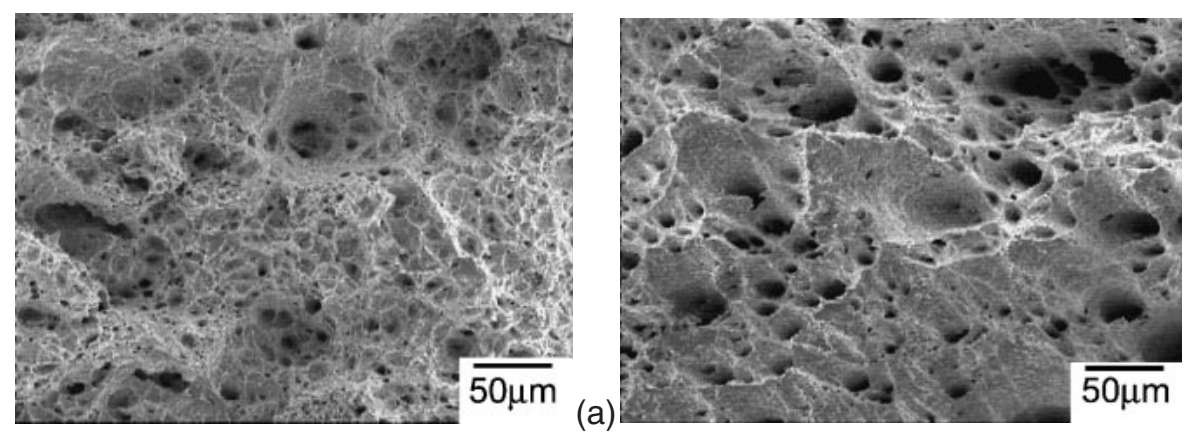

(e)
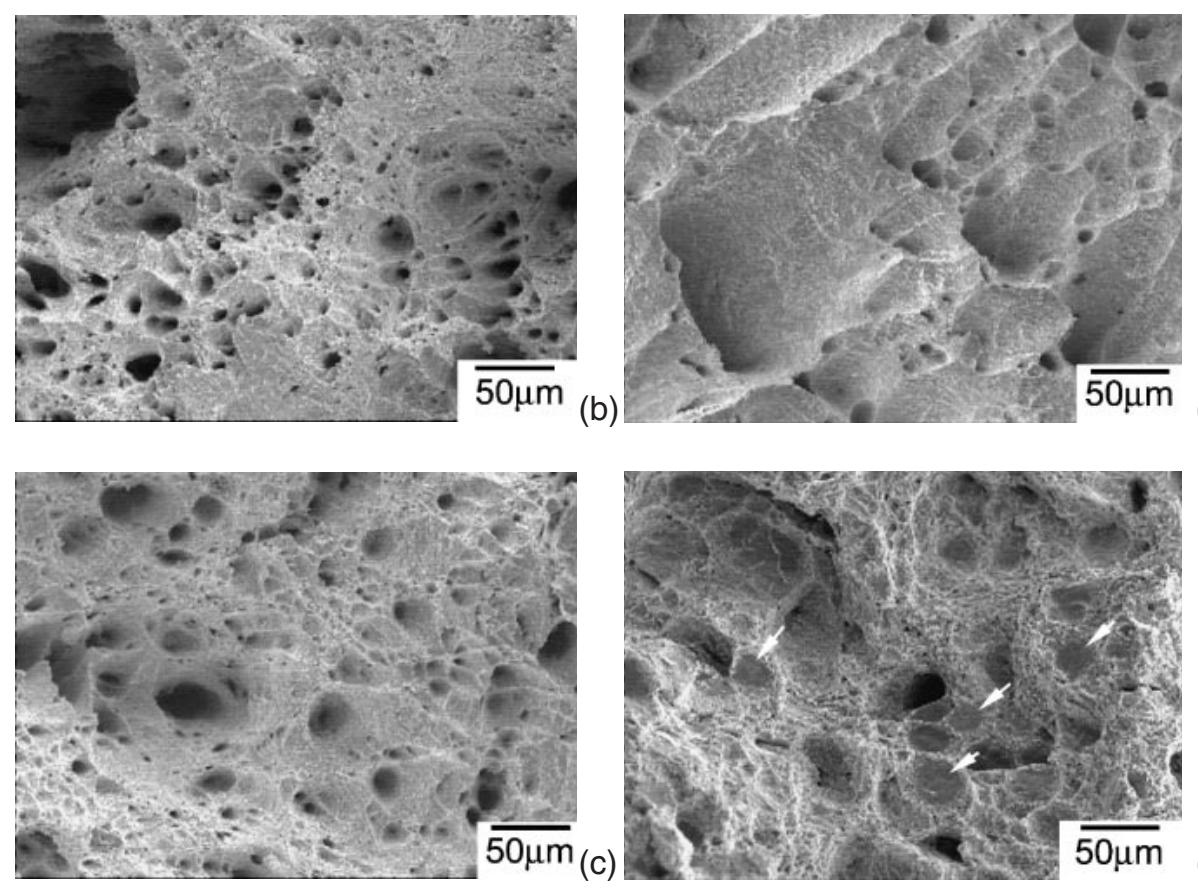

(g)
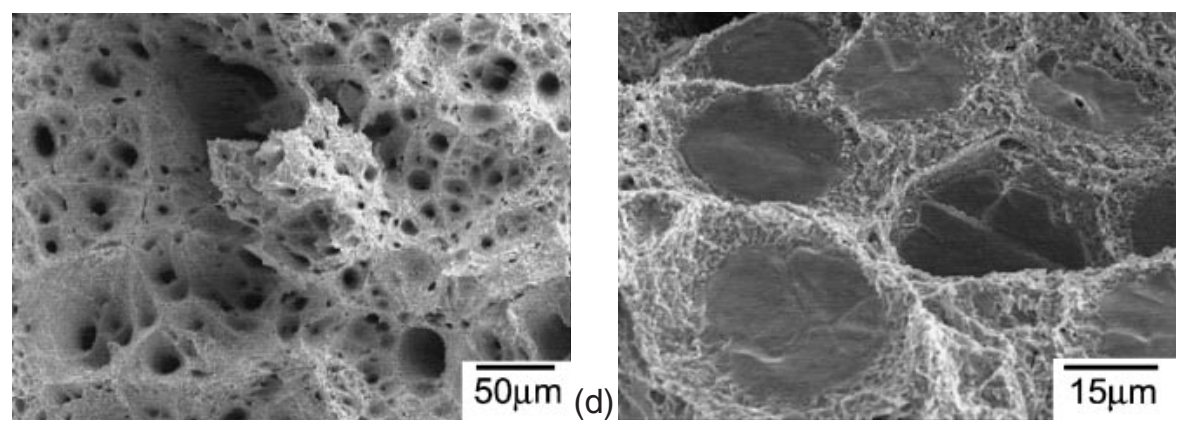

(h)

Fig. 10 Tensile fracture surface of the samples: (a) $0 \mathrm{Ga}$, (b) $0.05 \mathrm{Ga}$, (c) $0.1 \mathrm{Ga}$, (d) $0.25 \mathrm{Ga}$, (e) $0.5 \mathrm{Ga}$, (f) $1 \mathrm{Ga}$, (g) $1.8 \mathrm{Ga}$ (the arrows indicate the smooth facets) and (h) insert of (g).

transforms the microstructure into an irregular morphology. A further increase in $\mathrm{Ga}$ content converts the eutectic structure to a part-normal and part-irregular structure. This phenomenon is attributed to the composition variation of the solidification front. The initially solidified eutectic cells formed a normal morphology and then the residual liquid with a greater $\mathrm{Ga}$ content solidified to become the irregular eutectic structure at a lower temperature. Thus the alternate normal-irregular structure formed and the changed morphology and composition are gradual.

\subsection{Characteristics of a normal-irregular mixed struc- ture}

The results of cooling curves and DSC analysis indicate that the whole specimen maintains eutectic behavior regardless of the extent of Ga additions in the present study. Ga additions significantly lower the eutectic point of the Sn-Zn eutectic, and the reduction of temperature depends on the Ga content of each eutectic cell. Due to the normal-irregular mixed structure and the nonuniform $\mathrm{Ga}$ distribution, the melting range of the $\mathrm{Sn}-\mathrm{Zn}-\mathrm{Ga}$ alloys, particularly high Ga specimens, is enlarged.

The dissolution of $\mathrm{Ga}$ in $\mathrm{Sn}$ matrix results in the 
strengthening effect of $\mathrm{Ga}$ additions. In view of the fact that needle-like $\mathrm{Zn}$ phase is the preferred crack initiation site, ${ }^{13}$ ) reducing the fraction and rounding the shape of the $\mathrm{Zn}$ particles by Ga additions may contribute to the high uniform elongation in the high Ga specimen. On the other hand, the decohesion between the unusual massive Zn particles, Figs. $10(\mathrm{~g})$ and $(\mathrm{h})$, and matrix within irregular regions were probably responsible for the deterioration in the total elongation when the Ga content reaches 1.8 mass $\%$.

\section{Conclusions}

The addition of Ga significantly changes the microstructure characteristics, thermal properties and mechanical properties of the $\mathrm{Sn}-\mathrm{Zn}$ eutectic alloy. The alloy maintains eutectic behavior when the Ga content up to 1.8 mass $\%$. The dissolution of $\mathrm{Ga}$ in the $\mathrm{Sn}-\mathrm{Zn}$ eutectic significantly lowers the melting temperature, however, the inhomogeneous distribution of Ga expands the melting range. It also can be found that the enthalpy of fusion of the Sn-Zn eutectic alloy is about $70 \mathrm{~J} / \mathrm{g}$ regardless of $\mathrm{Ga}$ content. The eutectic structure in the vicinity of cell boundaries becomes irregular at less than 0.5 mass $\% \mathrm{Ga}$. The needle-like $\mathrm{Zn}$ phase becomes blunted, enlarged and less densely distributed. The irregular eutectic regions are extended and aligned alternately with normal structure at above 0.5 mass $\% \mathrm{Ga}$. The tensile strength of $\mathrm{Sn}-\mathrm{Zn}$ solders increases drastically with increasing $\mathrm{Ga}$ content and the elongation remains almost constant at less than 1.0 mass $\% \mathrm{Ga}$. On the other hand, a Ga content of exceeding 1.0 mass $\%$ results in a sharp drop in the total elongation but the improved ability against necking.

\section{Acknowledgments}

The authors acknowledge the financial support from National Science Council of R.O.C. under NSC 91-2216-E006-054.

\section{REFERENCES}

1) W. Yang and R. W. Messler Jr.: J. Electron. Mater. 23 (1994) 765-772.

2) H. Mavoori, J. Chin, S. Vaynman, B. Moran, L. Keer and M. E. Fine: J. Electron. Mater. 26 (1997) 783-790.

3) M. McCormack, S. Jin and G. W. Kammlott: Proceedings of the 1995 IEEE International Symposium on Electronics and the Environment, ISEE, May 1-3 1995, Orlando, FL, USA (1995) 171-176.

4) F. Hua and J. Glazer: Design \& Reliability of Solders and Solder Interconnections, (TMS Annual Meeting, 1997) 65-73.

5) S. Vaynman and M. E. Fine: Scr. Mater. 41 (1999) 1269-1271.

6) M. McCormack, S. Jin, H. S. Chen and D. A. Machusak: J. Electron. Mater. 23 (1994) 687-690.

7) I. Shohji, T. Nakamura, F. Mori and S. Fujiuchi: Mater. Trans. 43 (2002) 1797-1801.

8) K. L. Lin and T. P. Liu: Oxid. Met. 50 (1998) 255-267.

9) T. Takemoto, T. Funaki and A. Matsunawa: J. JPN Welding Soc. 17 (1999) 251-258

10) C. M. L. Wu, D. Q. Yu, C. M. T Law and L. Wang: J. Electron. Mater. 31 (2002) 921-927.

11) C. M. L. Wu, D. Q. Yu, C. M. T Law and L. Wang: J. Electron. Mater. 32 (2003) 63-69.

12) K. L. Lin and C. L. Shih: J. Electron. Mater. 32 (2003) 95-100.

13) J. M. Song, G. F. Lan, T. S. Lui and L. H. Chen: Scr. Mater. 48 (2003) 1047-1051.

14) K. I. Chen and K. L. Lin: J Electron. Mater. 31 (2002) 861-867.

15) K. L. Lin, L. H. Wen and T. P. Liu: J. Electron. Mater. 27 (1998) 97105.

16) J. S. Hwang, Z. Guo and H. Koenigsmann: Soldering and Surface Mount Technology 13/2 (2001) 7-13.

17) T. Shimizu, H. Ishikawa, I. Ohnuma and K. Ishida: J. Electron. Mater. 28 (1999) 1172-1175.

18) S. W. Yoon, J. R. Soh, H. M. Lee and B. J. Lee: Acta Mater. 45 (1997) 951-960.

19) S. W. Chen, C. C. Lin and C. M. Chen: Metall. Mater. Trans. A 29A (1998) 1965-1972.

20) T. J. Anderson and I. Ansara: J. Phase Equilibria. 13 (1992) 181-189.

21) J. Dutkiewicz, Z. Moser, L. Zabdyr, D. D. Gohil, T. G. Chart, I. Ansara and C. Girard: Bull. Alloy Phase Diagrams. 11 (1990) 77-82.

22) J. F. Shackelford: Introduction to Materials Science for Engineering, 2nd ed., (Macmillan publishing company, New York, 1988), p. 690.

23) F. Vnuk, M. Sahoo, D. Baragar and R. W. Smith: J. Mater. Sci. 15 (1980) 2573-2583.

24) R. Elliott and A. Moore: Scr. Metall. 3 (1969) 249-251.

25) R. Elliott: Mater. Sci. Eng. 65 (1984) 85-92. 